\title{
Atherosclerosis and Thrombosis: Insights from Large Animal Models
}

\author{
Gemma Vilahur, ${ }^{1,2}$ Teresa Padro, ${ }^{1,2}$ and Lina Badimon ${ }^{1,2,3}$ \\ ${ }^{1}$ Cardiovascular Research Center (CSIC-ICCC), Hospital de la Santa Creu i Sant Pau, IIB-Sant Pau, 08025 Barcelona, Spain \\ ${ }^{2}$ CIBERobn, Barcelona, Spain \\ ${ }^{3}$ Autonomous University of Barcelona (UAB), Barcelona, Spain
}

Correspondence should be addressed to Lina Badimon, lbadimon@csic-iccc.org

Received 23 September 2010; Accepted 9 December 2010

Academic Editor: Oreste Gualillo

Copyright (C) 2011 Gemma Vilahur et al. This is an open access article distributed under the Creative Commons Attribution License, which permits unrestricted use, distribution, and reproduction in any medium, provided the original work is properly cited.

\begin{abstract}
Atherosclerosis and its thrombotic complications are responsible for remarkably high numbers of deaths. The combination of in vitro, ex vivo, and in vivo experimental approaches has largely contributed to a better understanding of the mechanisms underlying the atherothrombotic process. Indeed, different animal models have been implemented in atherosclerosis and thrombosis research in order to provide new insights into the mechanisms that have already been outlined in isolated cells and protein studies. Yet, although no model completely mimics the human pathology, large animal models have demonstrated better suitability for translation to humans. Indeed, direct translation from mice to humans should be taken with caution because of the wellreported species-related differences. This paper provides an overview of the available atherothrombotic-like animal models, with a particular focus on large animal models of thrombosis and atherosclerosis, and examines their applicability for translational research purposes as well as highlights species-related differences with humans.
\end{abstract}

\section{Animal Models as a Tool for Preclinical Translation}

Atherosclerotic plaques may appear early in life and their advance into severe, symptomatic plaques, depends on the coexistence of risk factors. Rupture or damage of lipid- rich coronary plaques triggers subsequent thrombosis (i.e., atherothrombotic event), and this is possibly the most important mechanism leading to the onset of acute coronary syndromes (ACSs) and ischemic sudden death. Atherothrombosis involves a large number of platelet- and vessel- surface receptors, platelet-related signaling pathways, and the activation of the coagulation cascade all of which interplay to form the mural thrombotic clot [1]. In vitro studies have provided relevant information about mechanistic questions and have aided in the development of potent and selective antithrombotic drugs. Yet, in vivo approaches are necessary to address the hypothesis aimed at the prevention/treatment of human disease. Furthermore, in vitro research cannot mimic the hemodynamic and hemorrheology conditions that occur during the generation and propagation of thrombi in vivo, nor the vascular wall lesion resembling an atherosclerotic plaque. The availability of genetically modified mouse strains has enabled to elucidate new pathways involved in the development of cardiovascular disease [2]. However, although their usefulness in uncovering specific gene functions is overwhelming, their utility to extrapolate the findings to human disease or as preclinical models to prove validity pharmacologic agents is less appealing. Furthermore, it has been questioned whether these models should be trusted blindly, since compensating mechanisms and redundancies may affect their atherothrombotic phenotype. In contrast, the development and implementation of animal models of atherosclerosis and thrombosis, besides providing valuable information about the mechanisms involved in thrombus formations, have become valuable tools for the discovery of a number of compounds that, in fact, are now successfully being used for the 
treatment and prevention of the atherothrombotic diseases [3].

Rats, rabbits, dogs, pigs, and monkeys are well-established animal models of atherosclerosis and thrombosis whereas hamster, mouse, cat, and guinea pig have also been used, although to a lesser extent [14]. Overall, pigs and monkeys have been better suited to study atherosclerosis and arterial thrombosis than rats, rabbits and dogs. An ideal animal model should be representative of the human atherothrombotic disease but, unfortunately, the majority of assays are performed in healthy animals not addressing the underlying atherosclerotic cause. In addition, not all the large experimental animal models have human resemblance and validity and species-related differences should be regarded before interpreting the data. Table 1 highlights the major similarities and differences between humans and nonhuman primates, swine, and dogs in the thrombotic system.

\section{Small versus Large Animal Models}

Small animals, primarily rodents and rabbits, have been used extensively for atherosclerosis and thrombosis research [15]. Some of the reasons for the frequent use of small animal models in research include, low cost, ready availability, reduced ethical concern compared to large animals (especially nonhuman primates), and small size that limits the quantities of new agents required for in vivo screening. These characteristics have permitted rapid evaluation of new agents in sufficiently large number of animals to perform meaningful statistical analyses. However, mice do not develop atherosclerosis without genetic manipulation since they have a lipid physiology that is radically different from that in humans, most of the cholesterol being transported in HDLlike particles. Yet, their easy and practical handling, has made advantageous the use of murine models of vascular injury to study thrombosis [16]. In this regard, special attention should be given to the intravital microscopy usefulness in the mice model of thrombosis since it allows testing the in vivo relevance of the in vitro observations. Indeed, the study of microvascular thrombosis by intravital microscopy (e.g., mesenteric arteries) represents a particularly useful tool for characterization of specific cells types involved in the developing thrombus as well as evaluating the effect of different inflammatory pathological conditions, such as obesity, in vascular reactivity [17]. In addition, the dynamics of thrombus formation can be studied with very high resolution in these thin, transparent vessels thus providing a great insight into specific cellular and molecular interactions within the developing thrombus [18]. In addition, the rodent models offer numerous immunological approaches (e.g., monoclonal antibodies). Specifically, mice models provide genetically modified animal strains with defined defects in platelet function that open new ways to identify the individual roles and the interplay of platelet proteins in thrombus formation $[19,20]$. However, rodent microvascular models of thrombosis need to be complemented by macrovascular models of thrombosis in which vessel characteristics are more similar to human coronary, carotid, and cerebral arteries. As a result, large animal models may provide a more relevant representation of the type of thrombus formation that leads to clinical cardiovascular disease complications such as AMI and stroke. One example in which different results have been obtained between microvascular and macrovascular thrombosis models involved analysis of relevant tissue factor (TF) pools. Studies in groups using the same low-TF expressing mice reached different conclusions regarding the relevant source of TF in vascular thrombus formation, one group supporting the contribution of vessel-related TF [21], whereas the other emphasizes the key role of blood-borne $\mathrm{TF}$ as a major thrombogenic stimuli [22]. We and others, by using large animal models of thrombosis, have supported the hypothesis that vessel wall-derived TF is a primary contributor to arterial thrombus formation and propagation, yet, blood-borne TF may also contribute depending on the triggering lesion and the shear rate $[23,24]$.

Besides all this, an accurate in-depth determination of the mouse haemostatic system (i.e., coagulation and fibrinolytic systems, platelet structure, and platelet receptor/enzyme system) is still lacking, as nicely reviewed by Tsakiris et al, [25] and Ware [26], and species-related differences between rodents and humans should also be considered before interpreting the data. For instance, platelet counts in mice on average are four times those of humans and platelets are only approximately one half the volume of human platelets. All these reasons may help to explain why rodents have not been as widely used as larger animal models (e.g., swine) to test possible therapeutic usefulness of antithrombotic agents [27]. In fact, more advanced experimental models including nonhuman primates, pigs, and dogs are usually reserved to test the antithrombotic efficacy/safety of new compounds before clinical testing. Indeed, large animal models present disadvantages which are primarily the reverse of the advantages of small animal models (high cost, heightened ethical concerns, less precise genetic characterization, difficulties involved in maintaining the colonies and their handling and a scarcity of transgenic models, and antibodies); however, their human-resemblance makes them an attractive tool to provide new insights into the atherothrombotic field.

Because of similarities between human and nonhuman primates [28], nonhuman primate animal models are believed to be better suited to investigate human cardiovascular pathology (atherosclerosis, thrombus formation and dissolution, and therapeutic interventions). In 1965 Malinov and Maruffo [29] published studies performed using the monkey as animal model to evaluate aortic atherosclerosis. More recently, familial LDL receptor deficiency with atherosclerosis has been reported in rhesus monkey [30, 31]. Nonhuman primate thrombosis models, mainly arteriovenous shunt models are good models to evaluate novel thrombotic agents prior to administration of the drugs to human in clinical trials [32]. In fact, nonhuman primates platelet function, coagulation, and fibrinolytic system and drug pharmacokinetics resemble those in humans [28], and some immunologic overlap allows utilization of available assays. However, nowadays, the use of primates is constrained by obvious species specific (risk of extinction) and 
TABle 1: Differences between large animal models and humans in the thrombotic system and other parameters that may influence antithrombotic effectiveness.

\begin{tabular}{|c|c|c|c|}
\hline Specie & Differences with humans & Human similarities & Reference \\
\hline \multirow[t]{2}{*}{ Nonhuman primates } & & $\begin{array}{l}\text { Platelet function, coagulation, fibrinolysis } \\
\text { and therapeutic interventions } \\
\text { (arteriovenous vascular graft or surgical } \\
\text { endarterectomy) }\end{array}$ & Harker et al. [4] \\
\hline & Different digestive metabolic pathways & & Johnson et al. [5] \\
\hline \multirow{6}{*}{ Swine } & & Von Willebrand levels close to humans & Denis and Wagner [6] \\
\hline & & Physiological hematologic values & Gross [7] \\
\hline & $\begin{array}{l}\text { Accelerated intrinsic cascade activity } \\
\text { because of higher levels of coagulation } \\
\text { factors (IX, XI, XII) }\end{array}$ & & Olsen et al. [8] \\
\hline & $\begin{array}{l}\text { Iron deficiency that may affect } \\
\text { erythrocytic volumes }\end{array}$ & & Pedersen et al. [9] \\
\hline & GPIIb/IIIa protein & & Royo et al. [10] \\
\hline & Aortic EC do not contain mature vWF & & Royo and Badimon [11] \\
\hline \multirow[t]{2}{*}{ Dogs } & & $\begin{array}{l}\text { Vascular and platelet responsiveness to } \\
\text { thromboxane and endoperoxide } \\
\text { analogues close to humans }\end{array}$ & Burke et al. [12] \\
\hline & $\begin{array}{l}\text { Platelets appear to play a greater role in } \\
\text { thrombus formation than in humans }\end{array}$ & & Strony et al. [13] \\
\hline
\end{tabular}

EC: endothelial cells; VWF: Von Willebrand factor.

financial concerns, as well as the complexity, training and expertise required to perform this animal approach. This has supported the use of a more accessible and less costly large animal models, such as the porcine model, which fairly reproduces human atherosclerotic and thrombotic disease as detailed below.

\section{The Pig as a Tool for Atherothrombotic Disease}

The pig is a very good model because it develops spontaneous atherosclerotic lesions, has a human-like cardiovascular anatomy, and even may develop sudden death when under stress (White Belgian breed) [33-37]. In addition, swine offer the ability to evaluate their coronary arteries rather than larger central vessels (mostly studied in smaller animals).

The heart of the pig is anatomically similar to humans except for the presence of the left azygous (hemiazygous) vein, which drains the intercostal system into the coronary sinus [38], and for the size, which tends to be a bit smaller. Regarding the heart, blood supply is mostly right side dominant since it originates from the posterior septal artery [37] and both anatomy and function of the pig coronary system as well as the histological anatomy of the aorta are comparable to humans. However, on the other hand, pig blood vessels are more friable and prone to vasospasm during manipulation, and thus require careful handling during blood withdrawals [39]. In relation to pig hemodynamics, either physiological cardiac function or mechanically induced myocardial infarction and the subsequent arrhythmogenic activity in reperfusion is also analogous to humans as well as the wound healing process [40].
Pig atherosclerosis, diverging to small animal models, is generally quite slow and occurs both spontaneously (i.e., intake regular chow) and by experimental induction (i.e., intake of a high atherogenic diet) [41-43]. Moreover, if allowed to develop over time, mild atherosclerotic lesions first appear in coronary arteries and both atherosclerotic plaque distribution and composition (lipid, fibrinogen, smooth muscle cells, and macrophage content) [43] follows a pattern comparable to that of humans [44-46]. Humanlike pig lipoprotein metabolisms may help to explain, in part, the above mentioned similarities [47]. Finally, unlike other animal models, after gradual occlusion of the coronary vessels induced by both balloon injury and atherogenic diet, swine may develop the coronary restenosis syndrome as humans $[40,44,45,48,49]$.

Overall, literature reports three types of swine "atherothrombotic-like" approaches that may, sometimes, be combined including feeding animals with fat-rich diets, extracorporeal arteriovenous shunts, and intravascular damage interventions (balloon, grafting, etc).

3.1. Diet-Induced Atherosclerosis. As mentioned above, swine can develop hypercholesterolemia and atherosclerotic lesions by diet induction (high-cholesterol content diets), reaching plasma cholesterol levels similar to those in human. After a 50-day period with a standard hypercholesterolemic diet we have previously observed that almost all pigs developed early atherosclerotic lesions (fatty streaks) localized in the abdominal aorta and to a lesser extent in the coronary arteries [43]. In such cases, lesion composition was similar to early-stage human atherosclerosis [43]. As expected, increasing the diet induction period to 100 and 150 days was associated with a higher degree of lesion severity made 
evident when suitable fat stain was applied. Notwithstanding, animals employed in these long-period studies tend to be within the prepuberty period, and in consequence their lesions are not as severe as those developed in adult humans over the years. Older animals (over 6 months) can be used to obtain atherosclerotic models of higher human resemblance [50], but management becomes more difficult because of their considerable weight (up to $150 \mathrm{~kg}$ ). To overcome size-related problems, the minipigs are becoming increasingly used. Indeed, miniature swine are preferable to commercial swine as animal models because of their small size and small growth rate that allows them to maintain weight and size throughout adulthood. They are docile and easily handled and there are several miniature strains disposable to better fit scientific purposes. Miniature pigs have been used in several fields of biomedical research studies such as cardiovascular disease (models of thrombosis and restenosis), obesity, diabetes, and transplantation, however, the principal disadvantage for using miniature pigs as a substitute of common pigs are the maintenance requirements and the high cost of the animals. As a consequence, miniature pigs' breeders are not largely distributed in all countries.

3.2. Extracorporeal Arteriovenous Shunts. The ex vivo porcine model of thrombus formation (e.g., flow chambers coupled to extracorporeal shunts) has become essential for testing the effect of blood elements and rheology as well as atherosclerotic vessel components in thrombus formation in a controlled manner [1, 51-59]. Indeed, it has allowed to evaluate the thrombogenic effect of different atherosclerotic plaque constituents (e.g., collagen, fatty streaks, smooth muscle cells, etc) [51-53], different degrees of shear stress (to mimic different degrees of stenosis) $[54,55]$, and to evaluate the antiplatelet effects of new antithrombotic compounds $[43,53,55,58,60]$. Furthermore, these ex vivo models of thrombosis offer the opportunity to evaluate, in an easy and reproducible manner, the interaction of a given compound with the blood and vascular compartment and consider any metabolic transformation.

Baumgartner developed the first popular annular perfusion chamber that helped to advance the knowledge and understanding of platelet adhesion to the subendothelium under laminar flow [61]. Since then, other ex vivo chamber systems have been developed for investigating prosthetic and biologics substrates surfaces over a broad range of flow conditions $[62,63]$. In fact, although atherosclerosis preferentially occurs in areas of turbulent blood flow and low fluid shear stress, thrombosis is induced by high shear stress. Moreover, in atherosclerotic vessels, laminar flow conditions may not be maintained since stenotic narrowing induces flow disturbances that modify cell-cell and cell-vessel interactions as well as the local concentration of fluid-phase chemical mediators necessary for cell interaction. In this regard, we have developed an extracorporeal perfusion system (the Badimon chamber) [64] that allows to investigate the dynamics of platelet deposition and thrombus formation (a) on different surfaces (biological and prosthetic materials) $[65,66]$; (b) under a broad range of patho-physiological flow conditions including laminar and nonparallel streamline flows
$[54,67,68]$; (c) with varying perfusing blood treatments. This chamber has helped to improve the understanding of the pathophysiology of the acute coronary syndromes $[52,64]$, to characterize the thrombogenicity of different degrees of vascular injury [52] and different atheromatous components [51], evaluate the thrombogenicity associated to several synthetic/prosthetic surfaces $[65,66]$ and/or several plasma components (cholesterol, glucose levels, etc.) $[69,70]$ and has become a useful tool for the study and screen of new antithrombotic and platelet-inhibitory compounds upon exposure of human atherosclerotic and/or stented vessels $[51,53,55,71-75]$.

3.3. Intravascular Interventions. Coronary artery interventions, such as balloon angioplasty and stenting, have become established treatments for symptomatic coronary artery disease [76]. Although stent implantation initially appeared promising, with rates of $20 \%$ to $30 \%$ in so-called ideal lesions [77], there is still a high rate of vessel reclosure resulting in the need for repeat procedure [78]. Many animal models have provided insights into the mechanisms of angioplasty and in-stent restenosis in different metabolic disorders (obesity, diabetes, etc.) and are widely used to examine candidate drug inhibitors that might be used in clinical evaluation. Experience suggests, however, that porcine coronary stenting is a very suitable model because injury response is similar to human vessels with an adaptive response being more profound in animals fed a hypercholesterolemic diet [79]. Moreover, as stated above, since size and anatomic distribution of porcine coronary arteries are similar to those of the human, angiography, intravascular ultrasound, instrumentation, and stent deployment are all similar to the clinical situation. On the other hand, a number of strategies have also been adopted in an effort to reduce both the acute thrombogenic potential of metallic stents and the stent-induced neointimal thickening [80]. As such, oral administration of endothelin receptor antagonists [81] or tranilast [82], capable of modulating the inflammatory tissue responses, has been demonstrated to be efficacious in preventing neointima formation after coronary stenting in swine. Similarly, subcutaneous low-molecular-weight heparin administration on top of acetylsalicylic acid has also shown to reduce neointimal proliferation after coronary stent implantation in hypercholesterolemic minipigs [83]. In contrast, systemic pharmacological approaches in humans have been largely disappointing, possibly owing to insufficient local drug concentration. To solve this limitation, polymer coated stents were developed as a vehicle for local drug administration. To date, a number of diverse biological agents have been shown to elute slowly from polymer coatings and are associated with reduced neointima formation in pig models $[84,85]$.

\section{Canine Models of Atherosclerosis and Thrombosis}

The dog, as described for rats, is not a good model for atherosclerosis because they do not develop spontaneous 
atherosclerosis even under a high-cholesterol diet [86]. However, induction of experimental atherosclerosis in dogs has been achieved by administering high-fat/high-cholesterol diet deficient in essential fatty acids [87].

As to canine models of thrombosis, Folts and colleagues [88] described in 1976 a model of repetitive thrombus formation, assessed by cyclic flow reductions by an electromagnetic flow probe, in stenosed coronary arteries of open-chest anesthetized dogs. The Folts model is based on the combination of severe, concentric stenosis, and focal intimal injury canine coronaries (circumflex and left anterior descending) [3]. Yet, this model was lately modified for its use in both femoral and/or carotid rabbit arteries. The Folts model mainly induces platelet-rich thrombus formation. Hence, in contrast to the thrombi usually responsible for AMI, does not respond to thrombolytic agents likely representing a model of "thrombolytic-resistant" platelet occlusion rather than acute thrombosis. Nevertheless, this model is an attractive choice for initial antithrombotic effectiveness in vivo, especially for assessing prostaglandin-inhibitor compounds, prostacyclin mimetics, or platelet GPIIb/IIIa-receptor antagonists (e.g., abciximab, tirofiban, etc.) [89-92]. In fact, the preclinical data obtained with this animal model has been further corroborated in clinical trials such as the EPIC (abciximab) [93] and PRISM (tirofiban) investigators trials [94].

Canine thrombosis can also be challenged by advancing a thrombogenic coil into a coronary artery in closed-chest animals [95]. The composition (alloy) and size of the coil determine the time to occlusive thrombus formation confirmed by a filling defect distal to the coil. This model, in contrast to the Folts model, induces platelet-poor and fibrinrich thrombus and thus enables to test thrombolytic agents [96]. Important drawbacks, however, are the high incidence of ventricular fibrillations (which are around 20\%) and the requirement of expensive equipment and well-trained researchers which limits the efficiency of this approach. To overcome this disadvantages Bush and collaborators [97] developed a femoral artery version of this model that uses the same thrombogenicity coils but consists of Doppler flow probes placed proximal to the site of thrombosis and thus is also appropriate to use in rabbits.

Another model of coronary thrombosis in open-chest dogs is based on the local delivery of thrombin in the LAD coronary artery. This approach induces fibrin-rich clots amenable to lyse upon thrombolytic administration [98].

\section{Insights from Von Willebrand Disease in Large Animal Models}

Von Willebrand disease (VWd) is a genetic bleeding disorder that arises from the abnormalities in VW factor (VWF). It is the most common inherited bleeding disorder in humans, and over the past years several animal species have also been described as suffering from this disease whether through spontaneous mutation (pigs and dogs) or through a genetically engineered mutation (mice) [6]. All these different animal models have been extremely useful in exploring the characteristics of VWd and in testing new treatments. Indeed, the interaction of platelets with VWF is crucial in the initiation and development of any thrombotic process since enables platelets, via its surface glycoprotein receptors, to adhere to exposed subendothelium and to respond to blood shear stress [111-113]. In fact, we and Fuster et al. $[36,109]$ were among the first to show a striking difference in the atherosclerotic lesions in the aorta between normal pigs and VWd pigs, both in spontaneous and in dietinduced atherosclerosis, demonstrating protection against atherosclerosis in VWd pigs. The pig is a good model for studying VWd since VWF localization in endothelial cells and platelets mimics that of humans as do the clotting and platelet characteristics. Additionally, in normal pigs the level of VWF is close to the human level [6]. Canine VWd has also demonstrated to be similar to humans. Over the years, many dog breeds have been identified as suffering from this disease, making VWd the most common inherited bleeding disorder in dogs. However, under the term "canine VWd", there seems to be a very heterogeneous group of bleeding disorders with different subtypes and mode of inheritance [114]. Actually, canine VWd can vary in genetic transmission, clinical severity and diagnostic laboratory findings. Thus, in contrast to pigs, VWd dogs have not been used extensively for research purposes [115]. Finally, it deserves to be mentioned that VWd has also been reported in other animal species such as murine [116, 117], rabbits [118], and cats [119]. However, caution must be taken in extrapolating such results to the human clinical conditions.

\section{Animal Models of Plaque Rupture}

By its very nature, rupture of an atherosclerotic plaque is difficult to study in humans. Moreover, since rupture of an atherosclerotic plaque occurs in a stochastic fashion, it is also difficult to identify triggering factors and equally hard to investigate treatments addressed towards plaque stabilization. Thus, the appropriate animal model, not only should help to better understand the mechanisms behind plaque rupture but also test treatments to prevent it from happening. Despite the development of porcine models of advanced human-like coronary atherosclerosis, no suitable large animal model of high-risk (vulnerable) plaque exists. In fact, spontaneous hemorrhage and rupture is considered an extremely rare event in large animal models and has only been found in the coronary arteries of pigs with inherited hyper-low-density lipoprotein cholesterolemia or in cholesterol-fed pigs with streptozotocin-induced diabetes $[120,121]$. Lack of such a model has hampered studies designed to validate imaging technologies and to scrutinize the effects of therapeutic interventions in atherosclerotic arteries.

In the recent years, many rodent studies have been published with "vulnerable-like features". Some authors have described the presence of blood-filled channels within the advanced coronary lesions as well as plaque ruptures and thrombi in the aortic origin of old apolipoprotein $\mathrm{E}^{-/-}$(Apo $\left.\mathrm{E}^{-/-}\right)$mice $[122,123]$, whereas other studies have reported the presence of luminal thrombi in ruptured plaques of 
TABLE 2: Different animal models in order to evaluate thrombus formation.

\begin{tabular}{|c|c|c|}
\hline Reference & $\begin{array}{l}\text { Method applied in order to induce plaque rupture and/or thrombus } \\
\text { formation }\end{array}$ & Animal model \\
\hline Reddick et al. [99] & Forceps squeezing of the aorta & Apo $\mathrm{E}^{-/-}$mice \\
\hline $\begin{array}{l}\text { Gertz et al. [100] } \\
\text { Rekhter et al. [101] }\end{array}$ & $\begin{array}{l}\text { Combination of double ballon injury and hypercholesterolemia and further } \\
\text { angioplasty-induced plaque rupture }\end{array}$ & Rabbits \\
\hline Eitzman et al. [102] & Photochemical reaction to previously formed atherosclerotic plaques & Apo $\mathrm{E}^{-/-}$mice \\
\hline $\begin{array}{l}\text { Constantinides et al. [103] } \\
\text { Abela et al. [104] } \\
\text { Nakamura et al. [105] }\end{array}$ & $\begin{array}{l}\text { Intraperitoneal injection of Russell's viper venom* followed by i.v. injection } \\
\text { of histamine (vasopressor), serotonin or angiotensin II }\end{array}$ & Hypercholesterolemic rabbits \\
\hline Rekhter et al. [106] & $\begin{array}{l}\text { Intracerebroventricular injection of corticotrophin-releasing factors ("stress } \\
\text { hormone") }\end{array}$ & Apo $\mathrm{E}^{-/-}$mice \\
\hline Heras et al. [107] & Carotid angioplasty & Pig \\
\hline $\begin{array}{l}\text { Badimon et al. }[52,108] \\
\text { Lassila et al. }[65]\end{array}$ & $\begin{array}{l}\text { Thrombogenic effect of shear stress and atherosclerotic vessel components on } \\
\text { the extracorporeal perfusion system }\end{array}$ & Pig \\
\hline $\begin{array}{l}\text { Badimon et al. }[36] \\
\text { Fuster et al. }[109,110]\end{array}$ & Von Willebrand factor deficiency & $\begin{array}{l}\text { Pigs with von Willebrand } \\
\text { disease }\end{array}$ \\
\hline
\end{tabular}

${ }^{*}$ Procoagulant and endothelial toxin.

spontaneously dead Apo $\mathrm{E}^{-/-}$mice [124]. Yet, the relevance of these mice models of plaque rupture on the final events precipitated by plaque disruption of human atherosclerotic lesions is controversial, especially in animals surprisingly resistant to formation of thrombi at sites of atherosclerosis [125].

On the other hand, other investigators have evaluated the harmful effect of combining several risk factors. As such, it has been reported that either in double knockout mice with homozygous null mutations in the Apo $\mathrm{E}$ and the high-density lipoprotein (HDL) receptor, scavenger receptor class B, or combination of hypertension and dislipemia (hypertensive rats transgenic from human cholesteryl ester transfer protein) increase plaque vulnerability and thrombi formation.

Rabbits have been used as a model of plaque instability and rupture $[101,104]$, besides their extended use in animal models of atherogenesis $[100,126]$, myocardial infarction [127], and to evaluate the efficacy of new antithrombotic and anti-atherosclerotic drugs [128]. Moreover, transgenic rabbits have also been developed to obtain models of hereditary hyperlipidemia (WHHL-rabbit). Rabbits are easy to handle and cost-effective and there are three breeds of rabbits that have been commonly used in biomedical research: New Zealand White, Dutch Belted and Flemish Giant. Although rabbits do not develop spontaneous atherosclerosis, as they are vegetarian, we and others have robustly demonstrated that they can rapidly develop foam-cell-rich (fatty steaks) plaques after the administration of a rich atherosclerotic diet ( $0.5 \%-4 \%$ cholesterol content) during 8-16 weeks [129]. Yet, rabbit atherosclerotic lesions differ from human atheroma since their lipid and macrophage content is much higher as it is their hypercholesterolemic index [130]. Conversely, intermittent cycles of fat feeding with periods of normal diet has shown to induce plaques at more advanced stages that resemble human atheroma [131]. In addition, we have shown that combining cholesterol-rich feeding with arterial wall injury (e.g., balloon injury) induces advanced lesions in shorter periods [100, 104, 132-135].
The addition of pharmacological triggering at the end of the atherogenic diet has provided the first evidence of thrombosis associated with plaques in this experimental animal model, the Constantinides New Zealand white (CNZW) rabbit model, with similarities to thrombosis seen in human coronary arteries [103]. Furthermore, these observations have been supported by in vivo magnetic resonance imaging [136] and molecular-targeted imaging, using a fibrin binding peptide conjugated to gadolinium, which have clearly shown thrombus superimposition to the atherosclerotic lesion [137]. In counterpart, CNZW rabbit model similarity to human atherothrombosis has been questioned either because rabbits' atherosclerotic lesion composition (i.e., foam-cellrich rather than complicated plaques) and concerns about the triggering method used to induce plaque disruption and thrombosis [101, 130, 138].

Other more simplistic approaches (e.g., direct mechanical injury of the vessel of interest) with a lower impact for clinical translation have been also developed in different animal models as described in Table 2

\section{Animal Models of Venous Thrombosis}

Thrombogenesis in veins is mainly attributed to some combination of hypercoagulability, stasis, and vascular injury. All these triggering factors induce tissue thromboplastin (tissue factor) release to the flowing blood forming thrombin and fibrin that trap red blood cells. Thus, in contrast to arterial thrombotic lesions (platelet-rich thrombus, "white thrombus"), venous thrombosis is predominantly "red" and fibrin rich.

Animal models for venous thrombosis appear to be particularly useful for studying the pathophysiology of blood coagulation in vivo and the pathogenesis of venous thrombosis. For instance, this model has helped to define the role of activated protein $\mathrm{C}$, the interplay between inflammatory and procoagulant mediators, and the regulatory role of PAI-1 in thrombolysis besides therapeutic approaches [139]. In fact, 
Dörffler-Melly et al. [140] and Levi [139] have previously published interesting literature of small and large animal models of venous thrombosis, pointing out their advantages, usefulness, and limitations.

\section{Conclusions and Future Perspectives}

Clinical observations provide the substrate to build up pathophysiological hypotheses, but for obvious ethical reasons our ability to test these hypotheses in humans is very limited. Cell biology-related studies have helped to answer mechanistic questions, but lack complexity of a real disease thus limiting the scope of testable hypotheses. On the other hand, studies using rodent or large animal models have proved to be essential for proof of concept since they yield in vivo approaches to confirm critical hypotheses previously evaluated in relevant in vitro models. Experience over many decades has established that a single, naturally available model of human vascular disease does not exist. The advent of genetic engineering and the availability of transgenic and knockout animals have allowed pinpointing the relative functional importance of single changes in specific gene products. These approaches have permitted uncovering specific gene functions and have facilitated the formulation of new strategies for cardiovascular protection and the prevention and treatment of atherothrombosis. However, their utility as models of human disease and to prove the validity of products for human pharmacological use has not been demonstrated. Animal models have helped to accelerate the rate of new target identification and validation leading to improved therapeutics for the atherothrombotic disease. However, while small animal models provide experimental convenience and easiness to manipulate, more clinically relevant models are necessary to study the mechanisms involved in human atherothrombogenesis. Large animal models, although associated to a higher cost and handlingrelated difficulties, have shown an atherothrombotic pattern more comparable to that of humans. To date, considering all models, the porcine model is one of the most useful currently available atherothrombotic models. Indeed, pig animal models have shown to address specific questions related to blood and atherosclerotic vessel mechanisms involved in thrombus formation that have been eventually translated to clinical situations. Despite all this, efforts for developing the "ideal" animal model for atherothrombotic evaluation must continue as well as the development of state-of-the-art technology in order to achieve improved therapeutic strategies capable of further reducing the global burden of vascular atherothrombotic disease in humans.

\section{Acknowledgments}

This work was supported by PNS 2006-10091 (to Lina Badimon) from the Spanish Ministry of Science; Lilly Foundation (to Lina Badimon), CIBER OBN06 (to Lina Badimon), FIS PI071070 (to Teresa Padro) and REDINSCOR RD06/0003/0015 (to Teresa Padro). We thank Fundacion Jesús Serra, Barcelona, for their continuous support. Gemma
Vilahur is recipient of a Grant from the Spanish Ministry of Science and Innovation (RyC, MICINN).

\section{References}

[1] L. Badimón, G. Vilahur, and T. Padró, "Lipoproteins, platelets and atherothrombosis," Revista Espanola de Cardiologia, vol. 62, no. 10, pp. 1161-1178, 2009.

[2] K. L. Svenson, M. A. Bogue, and L. L. Peters, "Invited review: identifying new mouse models of cardiovascular disease: a review of high-throughput screens of mutagenized and inbred strains," Journal of Applied Physiology, vol. 94, no. 4, pp. 1650-1659, 2003.

[3] R. J. Shebuski, L. R. Bush, A. Gagnon, L. Chi, and R. J. Leadley Jr., "Development and applications of animal models of thrombosis," Methods in molecular medicine, vol. 93, pp. 175-219, 2004.

[4] L. A. Harker, A. B. Kelly, and S. R. Hanson, "Experimental arterial thrombosis in nonhuman primates," Circulation, vol. 83, no. 6, pp. V-41-V-55, 1991.

[5] G. J. Johnson, T. R. Griggs, and L. Badimon, "The utility of animal models in the preclinical study of interventions to prevent human coronary artery restenosis: analysis and recommendations," Thrombosis and Haemostasis, vol. 81, no. 5, pp. 835-843, 1999.

[6] C. V. Denis and D. D. Wagner, "Insights from von Willebrand disease animal models," Cellular and Molecular Life Sciences, vol. 56, no. 11-12, pp. 977-990, 1999.

[7] D. R. Gross, "Thromboembolic phenomena and the use of the pig as an appropriate animal model for research on cardiovascular devices," International Journal of Artificial Organs, vol. 20, no. 4, pp. 195-203, 1997.

[8] A. K. Olsen, A. K. Hansen, J. Jespersen, P. Marckmann, and E. M. Bladbjerg, "The pig as a model in blood coagulation and fibrinolysis research," Scandinavian Journal of Laboratory Animal Science, vol. 26, no. 4, pp. 214-224, 1999.

[9] S. Pedersen, I. Saeed, H. Friis, and K. F. Michaelsen, "Effect of iron deficiency on Trichuris suis and Ascaris suum infections in pigs," Parasitology, vol. 122, no. 5, pp. 589-598, 2001.

[10] T. Royo, M. Vidal, and L. Badimon, "Purification of the porcine platelet GP IIb-IIIa complex and the propolypeptide of von Willebrand factor," Thrombosis and Haemostasis, vol. 80, no. 2, pp. 302-309, 1998.

[11] T. Royo and L. Badimon, "The propolypeptide of von Willebrand factor (pp-vWF) is immunolocalized in the golgi apparatus of porcine aortic endothelial cells," Thrombosis and Haemostasis, 1999, (\# 1838) 583.

[12] S. E. Burke, A. M. Lefer, K. C. Nicolaou, G. M. Smith, and J. B. Smith, "Responsiveness of platelets and coronary arteries from different species to synthetic thromboxane and prostaglandin endoperoxide analogues," British Journal of Pharmacology, vol. 78, no. 2, pp. 287-292, 1983.

[13] J. Strony, A. Beaudoin, D. Brands, and B. Adelman, "Analysis of shear stress and hemodynamic factors in a model of coronary artery stenosis and thrombosis," American Journal of Physiology, vol. 265, no. 5, pp. H1787-H1796, 1993.

[14] P. F. Bodary and D. T. Eitzman, "Animal models of thrombosis," Current Opinion in Hematology, vol. 16, no. 5, pp. 342346, 2009.

[15] M. Narayanaswamy, K. C. Wright, and K. Kandarpa, "Animal models for atherosclerosis, restenosis, and endovascular graft research," Journal of Vascular and Interventional Radiology, vol. 11, no. 1, pp. 5-17, 2000. 
[16] U. J. H. Sachs and B. Nieswandt, "In vivo thrombus formation in murine models," Circulation Research, vol. 100, no. 7, pp. 979-991, 2007.

[17] L. Xiang, J. Naik, and R. L. Hester, "Exercise-induced increase in skeletal muscle vasodilatory responses in obese Zucker rats," American Journal of Physiology, vol. 288, no. 4, pp. R987-R991, 2005.

[18] B. Furie and B. C. Furie, "In vivo thrombus formation," Journal of Thrombosis and Haemostasis, vol. 5, no. 1, pp. 1217, 2007.

[19] B. Nieswandt, B. Aktas, A. Moers, and U. J. H. Sachs, "Platelets in atherothrombosis: lessons from mouse models," Journal of Thrombosis and Haemostasis, vol. 3, no. 8, pp. 1725-1736, 2005.

[20] P. Carmeliet, L. Moons, and D. Collen, "Mouse models of angiogenesis, arterial stenosis, atherosclerosis and hemostasis," Cardiovascular Research, vol. 39, no. 1, pp. 8-33, 1998.

[21] J. Chou, N. Mackman, G. Merrill-Skoloff, B. Pedersen, B. C. Furie, and B. Furie, "Hematopoietic cell-derived microparticle tissue factor contributes to fibrin formation during thrombus propagation," Blood, vol. 104, no. 10, pp. 3190-3197, 2004.

[22] S. M. Day, J. L. Reeve, B. Pedersen et al., "Macrovascular thrombosis is driven by tissue factor derived primarily from the blood vessel wall," Blood, vol. 105, no. 1, pp. 192-198, 2005.

[23] LI. Wang, C. Miller, R. F. Swarthout, M. Rao, N. Mackman, and M. B. Taubman, "Vascular smooth muscle-derived tissue factor is critical for arterial thrombosis after ferric chlorideinduced injury," Blood, vol. 113, no. 3, pp. 705-713, 2009.

[24] S. Sánchez-Gómez, L. Casani, G. Vilahur, and L. Badimon, "FFR-rFVIIa inhibits thrombosis triggered by ruptured and eroded vessel wall," Thrombosis and Haemostasis, 2001, abstract OC999.

[25] D. A. Tsakiris, L. Scudder, K. Hodivala-Dilke, R. O. Hynes, and B. S. Coller, "Hemostasis in the mouse (Mus musculus): a review," Thrombosis and Haemostasis, vol. 81, no. 2, pp. 177188, 1999.

[26] J. Ware, "Dysfunctional platelet membrane receptors: from humans to mice," Thrombosis and Haemostasis, vol. 92, no. 3, pp. 478-485, 2004.

[27] A. Farb, A. P. Burke, A. L. Tang et al., "Coronary plaque erosion without rupture into a lipid core: a frequent cause of coronary thrombosis in sudden coronary death," Circulation, vol. 93, no. 7, pp. 1354-1363, 1996.

[28] M. E. Todd, E. McDevitt, and E. I. Goldsmith, "Bloodclotting mechanisms of nonhuman primates. Choice of the baboon model to simulate man," Journal of Medical Primatology, vol. 1, no. 3, pp. 132-141, 1972.

[29] M. R. Malinow and C. A. Maruffo, "Aortic atherosclerosis in free-ranging howler monkeys (Alouatta caraya)," Nature, vol. 206, no. 4987, pp. 948-949, 1965.

[30] A. M. Scanu, A. Khalil, L. Neven et al., "Genetically determined hypercholesterolemia in a rhesus monkey family due to a deficiency of the LDL receptor," Journal of Lipid Research, vol. 29, no. 12, pp. 1671-1681, 1988.

[31] Y. Kusumi, A. M. Scanu, H. C. McGill, and R. W. Wissler, "Atherosclerosis in a rhesus monkey with genetic hypercholesterolemia and elevated plasma (Lp(a)," Atherosclerosis, vol. 99, no. 2, pp. 165-174, 1993.

[32] Y. Cadroy, S. R. Hanson, and L. A. Harker, "Antithrombotic effects of synthetic pentasaccharide with high affinity for plasma antithrombin III in non-human primates," Thrombosis and Haemostasis, vol. 70, no. 4, pp. 631-635, 1993.
[33] T. Royo, J. Alfón, M. Berrozpe, and L. Badimon, "Effect of gemfibrozil on peripheral atherosclerosis and platelet activation in a pig model of hyperlipidemia," European Journal of Clinical Investigation, vol. 30, no. 10, pp. 843-852, 2000.

[34] C. P. Palazón, J. Alfón, P. Gaffney, M. Berrozpe, T. Royo, and L. Badimon, "Effects of reducing LDL and increasing HDL with gemfibrozil in experimental coronary lesion development and thrombotic risk," Atherosclerosis, vol. 136, no. 2, pp. 333-345, 1998.

[35] V. Fuster, J. T. Lie, and L. Badimon, "Spontaneous and dietinduced coronary atherosclerosis in normal swine and swine with von Willebrand disease," Arteriosclerosis, vol. 5, no. 1, pp. 67-73, 1985.

[36] L. Badimon, P. Steele, and J. J. Badimon, "Aortic atherosclerosis in pigs with heterozygous von Willebrand disease. Comparison with homozygous von Willebrand and normal pigs," Arteriosclerosis, vol. 5, no. 4, pp. 366-370, 1985.

[37] T. Gardner and D. Johnson, "Cardiovascular system," in Experimental Surgery and Physiology: Induced Animal Models of Human Disease, M. M. Swindle and R. J. Adams, Eds., pp. 74-124, Lippincott, Williams \& Wilkins, Philadelphia, Pa, USA, 1988.

[38] M. M. Swindle, P. J. Horneffer, and T. J. Gardner, "Anatomic and anesthetic considerations in experimental cardiopulmonary surgery in swine," Laboratory Animal Science, vol. 36, no. 4, pp. 357-361, 1986.

[39] C. Bloor, F. White, and D. Roth, "The pig as a model of myocardial ischemia and gradual coronary artery occlusion," in Swine as Models in Biomedical Research, M. M. Swindle, Ed., pp. 163-175, Iowa State University Press, Ames, Iowa, USA, 1992.

[40] C. White, S. Ramee, A. Banks, D. Wiktor, and H. Price, "The Yucatan miniature swine: an atherogenic model to assess the early potency rates of an endovascular stent," in Swine as Models in Biomedical Research, M. M. Swindle, Ed., pp. 156162, Iowa State University Press, Ames, Iowa, USA, 1992.

[41] V. Fuster, L. Badimon, J. J. Badimon, J. H. Ip, and J. H. Chesebro, "The porcine model for the understanding of thrombogenesis and atherogenesis," Mayo Clinic Proceedings, vol. 66, no. 8, pp. 818-831, 1991.

[42] B. H. Skold, R. Getty, and F. K. Ramsey, "Spontaneous atherosclerosis in the arterial system of aging swine," American Journal of Veterinary Research, vol. 27, no. 116, pp. 257273, 1966.

[43] L. Casani, S. Sanchez-Gomez, G. Vilahur, and L. Badimon, "Pravastatin reduces thrombogenicity by mechanisms beyond plasma cholesterol lowering," Thrombosis and Haemostasis, vol. 94, no. 5, pp. 1035-1041, 2005.

[44] D. Gal, S. K. Chokshi, M. Mosseri, R. H. Clarke, and J. M. Isner, "Percutaneous delivery of low-level laser energy reverses histamine-induced spasm in atherosclerotic Yucatan microswine," Circulation, vol. 85, no. 2, pp. 756-768, 1992.

[45] F. C. White, S. M. Carroll, A. Magnet, and C. M. Bloor, "Coronary collateral development in swine after coronary artery occlusion," Circulation Research, vol. 71, no. 6, pp. 1490-1500, 1992.

[46] F. C. White and C. M. Bloor, "Coronary vascular remodeling and coronary resistance during chronic ischemia," American Journal of Cardiovascular Pathology, vol. 4, no. 3, pp. 193-202, 1992.

[47] C. A. Marzetta and L. L. Rudel, "A species comparison of low density lipoprotein heterogeneity in nonhuman primates fed 
atherogenic diets," Journal of Lipid Research, vol. 27, no. 7, pp. 753-762, 1986.

[48] M. M. Swindle, "Defining appropriate health status and management programs for specific-pathogen-free swine for xenotransplantation," Annals of the New York Academy of Sciences, vol. 862, pp. 111-120, 1998.

[49] H Stanton and H Mersmann, Swine in Cardiovascular Research, vol. 1 \& 2, CRC Press, Boca Raton, Fla, USA, 1986.

[50] L. Jørgensen, "The role of platelets in the initial stages of atherosclerosis," Journal of Thrombosis and Haemostasis, vol. 4, no. 7, pp. 1443-1449, 2006.

[51] A. Fernandez-Ortiz, J. J. Badimon, E. Falk et al., "Characterization of the relative thrombogenicity of atherosclerotic plaque components: implications for consequences of plaque rupture," Journal of the American College of Cardiology, vol. 23, no. 7, pp. 1562-1569, 1994.

[52] L. Badimon, J. J. Badimon, and A. Galvez, "Influence of arterial damage and wall shear rate on platelet deposition. Ex vivo study in a swine model," Arteriosclerosis, vol. 6, no. 3, pp. 312-320, 1986.

[53] G. Vilahur, X. Duran, O. Juan-Babot, L. Casaní, and L. Badimon, "Antithrombotic effects of saratin on human atherosclerotic plaques," Thrombosis and Haemostasis, vol. 92, no. 1, pp. 191-200, 2004.

[54] L. Badimon and J. J. Badimon, "Mechanisms of arterial thrombosis in nonparallel streamlines: platelet thrombi grow on the apex of stenotic severely injured vessel wall. Experimental study in the pig model," Journal of Clinical Investigation, vol. 84, no. 4, pp. 1134-1144, 1989.

[55] G. Vilahur, E. Segales, E. Salas, and L. Badimon, "Effects of a novel platelet nitric oxide donor (LA816), aspirin, clopidogrel, and combined therapy in inhibiting flow- and lesion-dependent thrombosis in the porcine ex vivo model," Circulation, vol. 110, no. 12, pp. 1686-1693, 2004.

[56] J. Roussi, N. Berge, C. Bal Dit Sollier et al., "Clopidogrelinduced qualitative changes in thrombus formation correlate with stent patency in injured pig cervical arteries," Thrombosis Research, vol. 105, no. 3, pp. 209-216, 2002.

[57] A. Mailhac, J. J. Badimon, J. T. Fallon et al., "Effect of an eccentric severe stenosis on fibrin(ogen) deposition on severely damaged vessel wall in arterial thrombosis: relative contribution of fibrin(ogen) and platelets," Circulation, vol. 90, no. 2, pp. 988-996, 1994.

[58] M. Roqué, U. Rauch, E. D. Reis, J. H. Chesebro, V. Fuster, and J. J. Badimon, "Comparative study of antithrombotic effect of a low molecular weight heparin and unfractionated heparin in an ex vivo model of deep arterial injury," Thrombosis Research, vol. 98, no. 6, pp. 499-505, 2000.

[59] D. Shimbo, J. Osende, J. Chen et al., "Antithrombotic effects of DX-9065a, a direct factor Xa inhibitor: a comparative study in humans versus low molecular weight heparin," Thrombosis and Haemostasis, vol. 88, no. 5, pp. 733-738, 2002.

[60] G. Vilahur, E. Segalés, L. Casaní, and L. Badimon, "A novel anti-ischemic nitric oxide donor inhibits thrombosis without modifying haemodynamics parameters," Thrombosis and Haemostasis, vol. 91, no. 5, pp. 1035-1043, 2004.

[61] H. R. Baumgartner, "The role of blood flow in platelet adhesion, fibrin deposition, and formation of mural thrombi," Microvascular Research, vol. 5, no. 2, pp. 167-179, 1973.

[62] K. S. Sakariassen, P. A. M. M. Aarts, and P. G. De Groot, "A perfusion chamber developed to investigate platelet interaction in flowing blood with human vessel wall cells, their extracellular matrix, and purified components," Journal of Laboratory and Clinical Medicine, vol. 102, no. 4, pp. 522$535,1983$.

[63] E. Martines, K. McGhee, C. Wilkinson, and A. Curtis, "A Parallel-plate flow chamber to study initial cell adhesion on a nanofeatured surface," IEEE Transactions on Nanobioscience, vol. 3, no. 2, pp. 90-95, 2004.

[64] L. Badimon, V. Turitto, J. A. Rosemark, J. J. Badimon, and V. Fuster, "Caracterization of a tubular flow chamber for studying platelet interaction with biologic and prosthetic materials: deposition of indium 111-labeled plateles on collagen, subendothelium and expanded polytetrafluoroethylene," Journal of Laboratory and Clinical Medicine, vol. 110, no. 6, pp. 706-718, 1987.

[65] R. Lassila, J. J. Badimon, S. Vallabhajosula, and L. Badimon, "Dynamic monitoring of platelet deposition on severely damaged vessel wall in flowing blood. Effects of different stenoses on thrombus growth," Arteriosclerosis, vol. 10, no. 2, pp. 306-315, 1990.

[66] L. Badimon, J. J. Badimon, V. T. Turitto, and V. Fuster, "Role of von Willebrand factor in platelet interaction with an expanded PTFE surface," ASAIO Transactions, vol. 33, no. 3, pp. 621-625, 1987.

[67] L. Badimon, J. J. Badimon, V. T. Turitto, and V. Fuster, "Thrombosis: studies under flow conditions," Annals of the New York Academy of Sciences, vol. 516, pp. 527-540, 1987.

[68] L. Badimon, J. J. Badimon, J. Rand, V. T. Turitto, and V. Fuster, "Platelet deposition on von Willebrand factordeficient vessels. Extracorporeal perfusion studies in swine with von Willebrand's disease using native and heparinized blood," Journal of Laboratory and Clinical Medicine, vol. 110, no. 5, pp. 634-647, 1987.

[69] J. J. Badimon, L. Badimon, V. T. Turitto, and V. Fuster, "Platelet deposition at higher shear rates is enhanced by high plasma cholesterol levels. In vivo study in the rabbit model," Arteriosclerosis and Thrombosis, vol. 11, no. 2, pp. 395-402, 1991.

[70] J. I. Osende, J. J. Badimon, V. Fuster et al., "Blood thrombogenicity in type 2 diabetes mellitus patients is associated with glycemic control," Journal of the American College of Cardiology, vol. 38, no. 5, pp. 1307-1312, 2001.

[71] G. Vilahur, L. Casani, and L. Badimon, "A thromboxane A/prostaglandin $\mathrm{H}$ receptor antagonist (S18886) shows high antithrombotic efficacy in an experimental model of stentinduced thrombosis," Thrombosis and Haemostasis, vol. 98, no. 3, pp. 662-669, 2007.

[72] G. Vilahur, M. I. Baldellou, E. Segalés, E. Salas, and L. Badimon, "Inhibition of thrombosis by a novel platelet selective S-nitrosothiol compound without hemodynamic side effects," Cardiovascular Research, vol. 61, no. 4, pp. 806816, 2004.

[73] G. Vilahur, E. Pena, T. Padró, and L. Badimon, "Protein disulphide isomerase-mediated LA419- NO release provides additional antithrombotic effects to the blockade of the ADP receptor," Thrombosis and Haemostasis, vol. 97, no. 4, pp. 650-657, 2007.

[74] M. U. Zafar, G. Vilahur, B. G. Choi et al., "A novel antiischemic nitric oxide donor (LA419) reduces thrombogenesis in healthy human subjects," Journal of Thrombosis and Haemostasis, vol. 5, no. 6, pp. 1195-1200, 2007.

[75] E. I. Lev, D. Hasdai, E. Scapa et al., "Administration of eptifibatide to acute coronary syndrome patients receiving enoxaparin or unfractionated heparin: effect on platelet function and thrombus formation," Journal of the American College of Cardiology, vol. 43, no. 6, pp. 966-971, 2004. 
[76] Institute of Laboratory Animal Resources, Commission on Life Sciences, National Research Council, Guide for the Care and Use of Laboratory Animals, National Academy Press, Washington, DC, USA, 1996.

[77] E. R. Edelman and C. Rogers, "Pathobiologic responses to stenting," American Journal of Cardiology, vol. 81, no. 7A, pp. 4E-6E, 1998.

[78] H. C. Lowe, S. N. Oesterle, and L. M. Khachigian, "Coronary in-stent restenosis: current status and future strategies," Journal of the American College of Cardiology, vol. 39, no. 2, pp. 183-193, 2002.

[79] G. P. Rodgers, S. T. Minor, K. Robinson et al., "Adjuvant therapy for intracoronary stents. Investigations in atherosclerotic swine," Circulation, vol. 82, no. 2, pp. 560-569, 1990.

[80] A. H. Gershlick and J. Baron, "Dealing with in-stent restenosis," Heart, vol. 79, no. 4, pp. 319-323, 1998.

[81] M. Kirchengast, "Endothelin receptor blockade and in-stent restenosis," Journal of Cardiovascular Pharmacology, vol. 38, no. 2, pp. S31-S34, 2002.

[82] S. Ishiwata, S. Verheye, K. A. Robinson et al., "Inhibition of neointima formation by tranilast in pig coronary arteries after balloon angioplasty and stent implantation," Journal of the American College of Cardiology, vol. 35, no. 5, pp. 13311337, 2000.

[83] A. B. Buchwald, C. Unterberg, K. Nebendahl, H. J. Grone, and V. Wiegand, "Low-molecular-weight heparin reduces neointimal proliferation after coronary stent implantation in hypercholesterolemic minipigs," Circulation, vol. 86, no. 2, pp. 531-537, 1992.

[84] I. De Scheerder, K. Wang, K. Wilczek et al., "Local methylprednisolone inhibition of foreign body response to coated intracoronary stents," Coronary Artery Disease, vol. 7, no. 2, pp. 161-166, 1996.

[85] E. Alt, I. Haehnel, C. Beilharz et al., "Inhibition of neointima formation after experimental coronary artery stenting: a new biodegradable stent coating releasing hirudin and the prostacyclin analogue iloprost," Circulation, vol. 101, no. 12, pp. 1453-1458, 2000.

[86] R. W. Mahley, K. H. Weisgraber, and T. Innerarity, "Canine lipoproteins and atherosclerosis. II. Characterization of the plasma lipoproteins associated with atherogenic and nonatherogenic hyperlipidemia," Circulation Research, vol. 35, no. 5, pp. 722-733, 1974.

[87] A. Butkus, L. A. Ehrhart, and K. G. McCullagh, "Plasma and aortic lipids in experimental canine atherosclerosis," Experimental and Molecular Pathology, vol. 25, no. 2, pp. 152$162,1976$.

[88] J. D. Folts, E. B. Crowell Jr., and G. G. Rowe, "Platelet aggregation in partially obstructed vessels and its elimination with aspirin," Circulation, vol. 54, no. 3, pp. 365-370, 1976.

[89] J. W. Aiken, R. R. Gorman, and R. J. Shebuski, "Prevention of blockage of partially obstructed coronary arteries with prostacyclin correlates with inhibition of platelet aggregation," Prostaglandins, vol. 17, no. 4, pp. 483-494, 1979.

[90] J. D. Folts, K. Gallagher, and G. G. Rowe, "Blood flow reductions in stenosed canine coronary arteries: vasospasm or platelet aggregation?" Circulation, vol. 65, no. 2, pp. 248 255, 1982.

[91] M. A. Holahan, M. J. Mellott, V. M. Garsky, and R. J. Shebuski, "Prevention of reocclusion following tissue type plasminogen activator-induced thrombolysis by the RGDcontaining peptide, echistatin, in a canine model of coronary thrombosis," Pharmacology, vol. 42, no. 6, pp. 340-348, 1991.
[92] B. S. Coller and L. E. Scudder, "Inhibition of dog platelet function by in vivo infusion of $\mathrm{F}(\mathrm{ab}$ ') fragments of a monoclonal antibody to the platelet glycoprotein IIb/IIIa receptor," Blood, vol. 66, no. 6, pp. 1456-1459, 1985.

[93] R. M. Califf, "Use of a monoclonal antibody directed against the platelet glycoprotein IIb/IIIa receptor in high-risk coronary angioplasty," New England Journal of Medicine, vol. 330, no. 14, pp. 956-961, 1994.

[94] P. Théroux, "Inhibition of the platelet glycoprotein IIb/IIIa receptor with tirofiban in unstable angina and non-Q-wave myocardial infarction," New England Journal of Medicine, vol. 338, no. 21, pp. 1488-1497, 1998.

[95] S. R. Bergmann, K. A. A. Fox, and M. M. Ter Pogossian, "Clot-selective coronary thrombolysis with tissue-type plasminogen activator," Science, vol. 220, no. 4602, pp. 11811183, 1983.

[96] P. Golino, J. H. Ashton, P. Glas-Greenwalt, J. McNatt, L. M. Buja, and J. T. Willerson, "Mediation of reocclusion by thromboxane $\mathrm{A}_{2}$ and serotonin after thrombolysis with tissue-type plasminogen activator in a canine preparation of coronary thrombosis," Circulation, vol. 77, no. 3, pp. 678684, 1988.

[97] L. R. Bush, M. J. Mellott, S. M. Kanovsky, M. A. Holahan, and D. H. Patrick, "A model of femoral artery thrombolysis in dogs," Fibrinolysis, vol. 3, no. 2, pp. 107-114, 1989.

[98] H. K. Gold, J. T. Fallon, and T. Yasuda, "Coronary thrombolysis with recombinant human tissue-type plasminogen activator," Circulation, vol. 70, no. 4, pp. 700-707, 1984.

[99] R. L. Reddick, S. H. Zhang, and N. Maeda, "Aortic atherosclerotic plaque injury in apolipoprotein E deficient mice," Atherosclerosis, vol. 140, no. 2, pp. 297-305, 1998.

[100] S. D. Gertz, J. T. Fallon, R. Gallo et al., "Hirudin reduces tissue factor expression in neointima after balloon injury in rabbit femoral and porcine coronary arteries," Circulation, vol. 98, no. 6, pp. 580-587, 1998.

[101] M. D. Rekhter, G. W. Hicks, D. W. Brammer et al., "Animal model that mimics atherosclerotic plaque rupture," Circulation Research, vol. 83, no. 7, pp. 705-713, 1998.

[102] D. T. Eitzman, R. J. Westrick, Z. Xu, J. Tyson, and D. Ginsburg, "Hyperlipidemia promotes thrombosis after injury to atherosclerotic vessels in apolipoprotein E-deficient mice," Arteriosclerosis, Thrombosis, and Vascular Biology, vol. 20, no. 7, pp. 1831-1834, 2000.

[103] P. Constantinides and R. N. Chakravarti, "Rabbit arterial thrombosis production by systemic procedures," Archives of Pathology, vol. 72, pp. 197-208, 1961.

[104] G. S. Abela, P. D. Picon, S. E. Friedl et al., "Triggering of plaque disruption and arterial thrombosis in an atherosclerotic rabbit model," Circulation, vol. 91, no. 3, pp. 776-784, 1995.

[105] M. Nakamura, S. Abe, and N. Kinukawa, "Aortic medial necrosis with or without thrombosis in rabbits treated with Russell's viper venom and angiotensin II," Atherosclerosis, vol. 128, no. 2, pp. 149-156, 1997.

[106] M. D. Rekhter, G. W. Hicks, D. W. Brammer et al., "Hypercholesterolemia causes mechanical weakening of rabbit atheroma: local collagen loss as a prerequisite of plaque rupture," Circulation Research, vol. 86, no. 1, pp. 101-108, 2000.

[107] M. Heras, J. H. Chesebro, W. J. Penny, K. R. Bailey, L. Badimon, and V. Fuster, "Effects of thrombin inhibition on the development of acute platelet-thrombus deposition during angioplasty in pigs. Heparin versus recombinant 
hirudin, a specific thrombin inhibitor," Circulation, vol. 79, no. 3, pp. 657-665, 1989.

[108] L. Badimon, J. J. Badimon, V. T. Turitto, S. Vallabhajosula, and V. Fuster, "Platelet thrombus formation on collagen type I. A model of deep vessel injury: Influence of blood rheology, von Willebrand factor, and blood coagulation," Circulation, vol. 78, no. 6, pp. 1431-1442, 1988.

[109] W. Fuster, E. J. Bowie, J. C. Lewis, D. N. Fass, C. A. Owen, and A. L. Brown, "Resistance to arteriosclerosis in pigs with von Willebrand's disease. Spontaneous and high cholesterol dietinduced arteriosclerosis," Journal of Clinical Investigation, vol. 61, no. 3, pp. 722-730, 1978.

[110] V. Fuster, D. N. Fass, and M. P. Kaye, "Arteriosclerosis in normal and von Willebrand pigs. Long-term prospective study and aortic transplantation study," Circulation Research, vol. 51, no. 5, pp. 587-593, 1982.

[111] Z. M. Ruggeri, J. N. Orje, R. Habermann, A. B. Federici, and A. J. Reininger, "Activation-independent platelet adhesion and aggregation under elevated shear stress," Blood, vol. 108, no. 6, pp. 1903-1910, 2006.

[112] A. J. Reininger, H. F. G. Heijnen, H. Schumann, H. M. Specht, W. Schramm, and Z. M. Ruggeri, "Mechanism of platelet adhesion to von Willebrand factor and microparticle formation under high shear stress," Blood, vol. 107, no. 9, pp. 3537-3545, 2006.

[113] R. Donadelli, J. N. Orje, C. Capoferri, G. Remuzzi, and Z. M. Ruggeri, "Size regulation of von Willebrand factor-mediated platelet thrombi by ADAMTS13 in flowing blood," Blood, vol. 107, no. 5, pp. 1943-1950, 2006.

[114] G. S. Johnson, M. A. Turrentine, and K. H. Kraus, "Canine von Willebrand's disease. A heterogeneous group of bleeding disorders," Veterinary Clinics of North America. Small Animal Practice, vol. 18, no. 1, pp. 195-229, 1988.

[115] T. C. Nichols, D. A. Bellinger, R. L. Reddick et al., "The roles of von Willebrand factor and factor VIII in arterial thrombosis: studies in canine von Willebrand disease and hemophilia A," Blood, vol. 81, no. 10, pp. 2644-2651, 1993.

[116] J. D. Sweeney, E. K. Novak, M. Reddington, K. H. Takeuchi, and R. T. Swank, "The RIIIS/J inbred mouse strain as a model for von Willebrand disease," Blood, vol. 76, no. 11, pp. 22582265, 1990.

[117] C. Denis, N. Methia, P. S. Frenette et al., "A mouse model of severe von Willebrand disease: defects in hemostasis and thrombosis," Proceedings of the National Academy of Sciences of the United States of America, vol. 95, no. 16, pp. 9524-9529, 1998.

[118] R. Benson and W. Dodds, "Autosomal factor VIII deficiency in rabbits:size variations of rabbit factor VIII," Thrombosis and Haemostasis, vol. 38, p. 380, 1977.

[119] T. W. French, L. E. Fox, J. F. Randolph, and W. J. Dodds, "A bleeding disorder (von Willebrand's disease) in a Himalayan cat," Journal of the American Veterinary Medical Association, vol. 190, no. 4, pp. 437-439, 1987.

[120] M. F. Prescott, C. H. McBride, J. Hasler-Rapacz, J. Von Linden, and J. Rapacz, "Development of complex atherosclerotic lesions in pigs with inherited hyper-LDL cholesterolemia bearing mutant alleles for apolipoprotein B," American Journal of Pathology, vol. 139, no. 1, pp. 139-147, 1991.

[121] R. G. Gerrity, R. Natarajan, J. L. Nadler, and T. Kimsey, "Diabetes-induced accelerated atherosclerosis in swine," Diabetes, vol. 50, no. 7, pp. 1654-1665, 2001.

[122] M. E. Rosenfeld, P. Polinsky, R. Virmani, K. Kauser, G. Rubanyi, and S. M. Schwartz, "Advanced atherosclerotic lesions in the innominate artery of the apoE knockout mouse," Arteriosclerosis, Thrombosis, and Vascular Biology, vol. 20, no. 12, pp. 2587-2592, 2000.

[123] F. Calara, M. Silvestre, F. Casanada, N. Yuan, C. Napoli, and W. Palinski, "Spontaneous plaque rupture and secondary thrombosis in apolipoprotein E-deficient and LDL receptordeficient mice," Journal of Pathology, vol. 195, no. 2, pp. 257263, 2001.

[124] J. L. Johnson and C. L. Jackson, "Atherosclerotic plaque rupture in the apolipoprotein E knockout mouse," Atherosclerosis, vol. 154, no. 2, pp. 399-406, 2001.

[125] S. M. Schwartz, Z. S. Galis, M. E. Rosenfeld, and E. Falk, "Plaque rupture in humans and mice," Arteriosclerosis, Thrombosis, and Vascular Biology, vol. 27, no. 4, pp. 705-713, 2007.

[126] L. Badimon, V. Fuster, J. H. Chesebro, and M. K. Dewanjee, "New "ex vivo" radioisotopic method of quantitation of platelet deposition - studies in four animal species," Thrombosis and Haemostasis, vol. 50, no. 3, pp. 639-644, 1983.

[127] M. Shiomi, T. Ito, S. Yamada, S. Kawashima, and J. Fan, "Correlation of vulnerable coronary plaques to sudden cardiac events. Lessons from a myocardial infarction-prone animal model (the WHHLMI rabbit)," Journal of atherosclerosis and thrombosis, vol. 11, no. 4, pp. 184-189, 2004.

[128] J. Alfon, C. Pueyo Palazon, T. Royo, and L. Badimon, "Effects of statins in thrombosis and aortic lesion development in a dyslipemic rabbit model," Thrombosis and Haemostasis, vol. 81, no. 5, pp. 822-827, 1999.

[129] J. J. Badimon, L. Badimon, and V. Fuster, "Regression of atherosclerotic lesions by high density lipoprotein plasma fraction in the cholesterol-fed rabbit," Journal of Clinical Investigation, vol. 85, no. 4, pp. 1234-1241, 1990.

[130] L. Badimon, "Atherosclerosis and thrombosis: lessons from animal models," Thrombosis and Haemostasis, vol. 86, no. 1, pp. 356-365, 2001.

[131] P. Constantinides, J. Booth, and G. Carlson, "Production of advanced cholesterol atherosclerosis in the rabbit," Archives of Pathology, vol. 70, pp. 712-724, 1960.

[132] B. Ibanez, G. Vilahur, G. Cimmino et al., "Rapid change in plaque size, composition, and molecular footprint after recombinant apolipoprotein A- $\mathrm{I}_{\text {Milano }}$ (ETC-216) administration: magnetic resonance imaging study in an experimental model of atherosclerosis," Journal of the American College of Cardiology, vol. 51, no. 11, pp. 1104-1109, 2008.

[133] G. Cimmino, B. Ibanez, G. Vilahur et al., "Up-regulation of reverse cholesterol transport key players and rescue from global inflammation by ApoA- $\mathrm{I}_{\text {Milano," Journal of Cellular and }}$ Molecular Medicine, vol. 13, no. 9B, pp. 3226-3235, 2009.

[134] B. G. Choi, G. Vilahur, M. U. Zafar et al., "Selective estrogen receptor modulation influences atherosclerotic plaque composition in a rabbit menopause model," Atherosclerosis, vol. 201, no. 1, pp. 76-84, 2008.

[135] B. G. Choi, G. Vilahur, L. Cardoso et al., "Ovariectomy increases vascular calcification via the OPG/RANKL cytokine signalling pathway," European Journal of Clinical Investigation, vol. 38, no. 4, pp. 211-217, 2008.

[136] M. T. Johnstone, R. M. Botnar, A. S. Perez et al., "In vivo magnetic resonance imaging of experimental thrombosis in a rabbit model," Arteriosclerosis, Thrombosis, and Vascular Biology, vol. 21, no. 9, pp. 1556-1560, 2001.

[137] R. M. Botnar, A. S. Perez, S. Witte et al., "In vivo molecular imaging of acute and subacute thrombosis using a fibrinbinding magnetic resonance imaging contrast agent," Circulation, vol. 109, no. 16, pp. 2023-2029, 2004. 
[138] R. W. Wissler and D. Vesselinovitch, Differences between Human and Animal Atherosclerosis, Springer, New York, NY, USA, 1974.

[139] M. Levi, J. Dörffler-Melly, G. J. Johnson, L. Drouet, and L. Badimon, "Usefulness and limitations of animal models of venous thrombosis," Thrombosis and Haemostasis, vol. 86, no. 5, pp. 1331-1333, 2001.

[140] J. Dörffler-Melly, L. A. Schwarte, C. Ince, and M. Levi, "Mouse models of focal arterial and venous thrombosis," Basic Research in Cardiology, vol. 95, no. 6, pp. 503-509, 2000. 


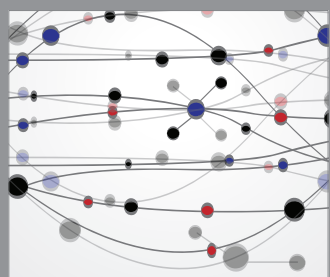

The Scientific World Journal
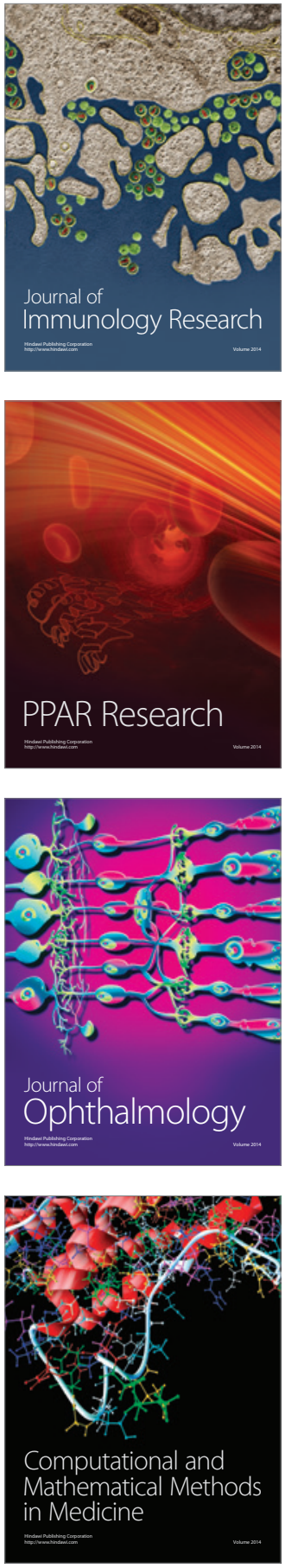

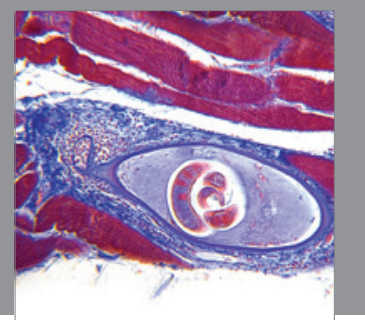

Gastroenterology

Research and Practice
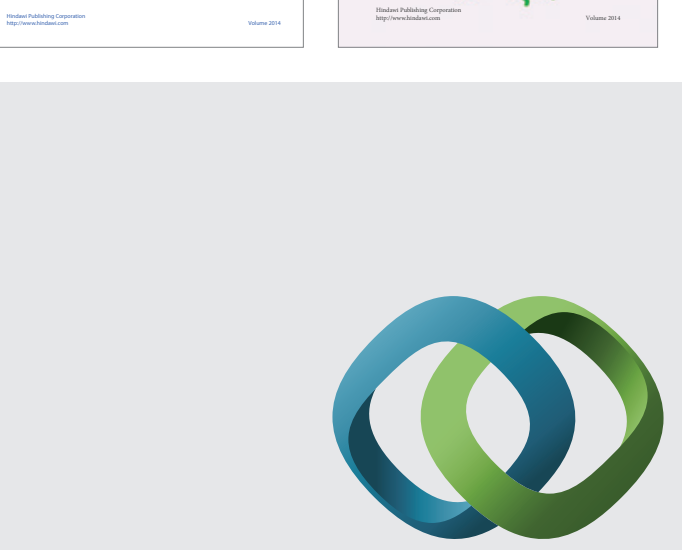

\section{Hindawi}

Submit your manuscripts at

http://www.hindawi.com
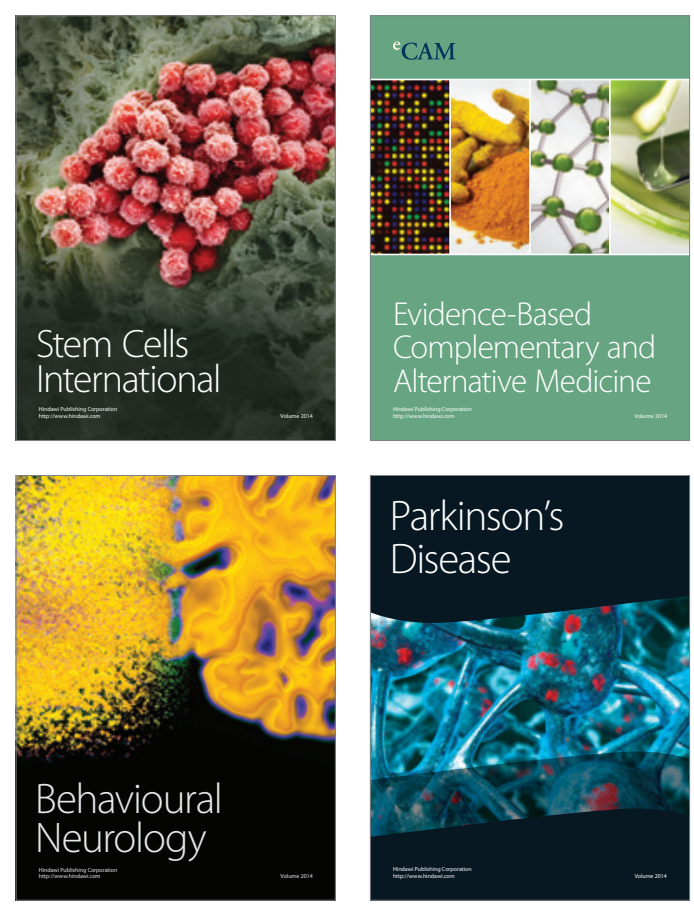

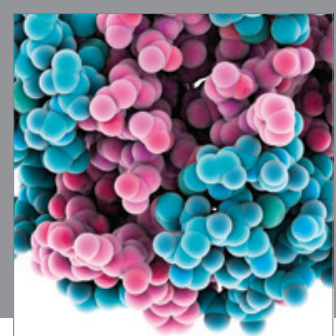

Journal of
Diabetes Research

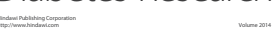

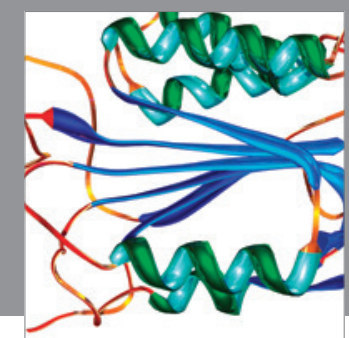

Disease Markers
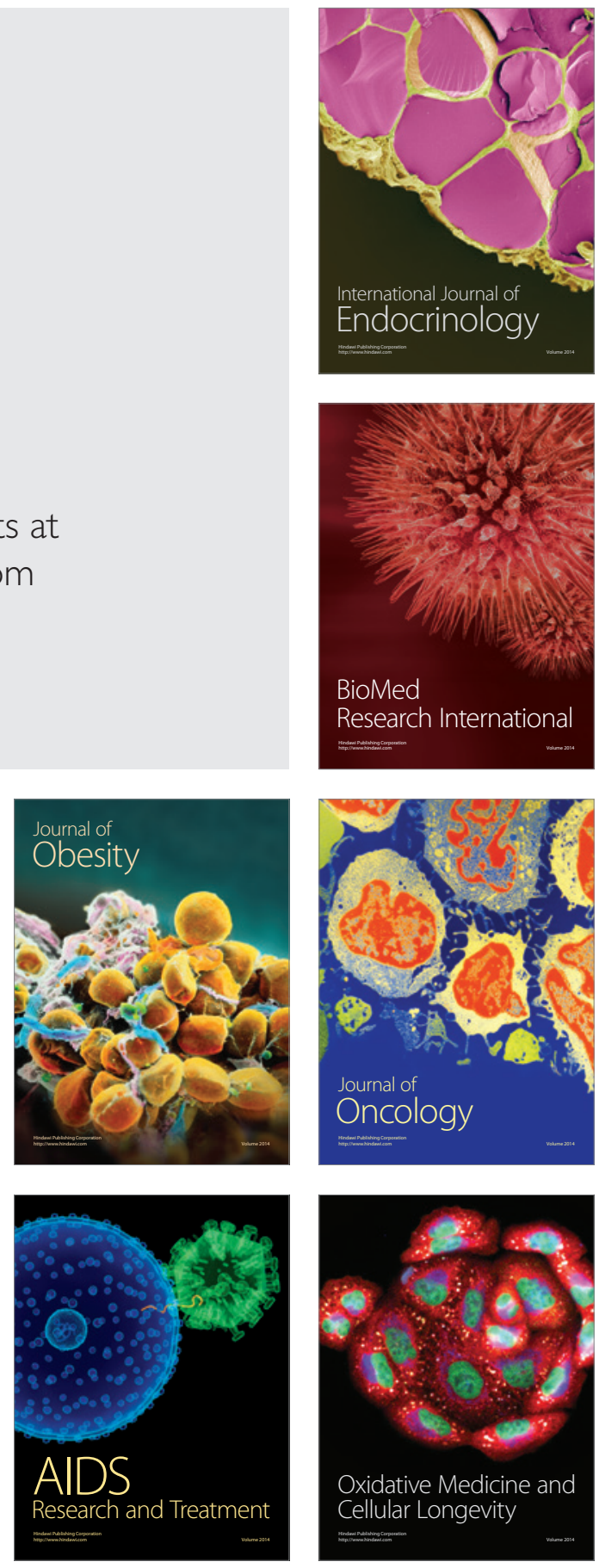